\title{
El derecho a migrar o ius migrandi como derecho fundamental implícito
}

\section{The right to migrate or ius migrandi as an implied fundamental right}

\author{
VÍCtor Araya Madariaga $^{1}$
}

\begin{abstract}
RESUMEN
La migración ha acompañado el desarrollo humano desde siempre. Sin embargo, con la consolidación de las fronteras y del Estado nación, la movilidad humana se ha visto restringida producto de regulaciones principalmente internas de cada Estado. Radicarse en un territorio distinto al de origen, en busca de nuevas posibilidades, que en un principio fue un derecho no controvertido, hoy es más bien una concesión del Estado de destino. La reflexión propuesta en este artículo pretende rescatar la concepción del ius migrandi como un derecho fundamental inherente al individuo, que desde su aparición se ha trasladado de un lugar a otro en busca de alimento, seguridad o solo por curiosidad, buscando siempre su máximo desarrollo. Hoy se reconoce el derecho a la libre circulación dentro del territorio y el derecho a salir del Estado. Sin embargo, este derecho se torna ilusorio si no tiene como correlato un derecho a ingresar a otro Estado. El derecho a migrar comprende ambos derechos, emigrar e inmigrar, y se configura dentro del marco teórico de los derechos humanos como un derecho implícito, derivado de la dignidad humana y del derecho a la libre circulación.
\end{abstract}

Palabras clave: derecho a migrar, ius migrandi, movilidad humana, libertad ambulatoria, derechos fundamentales, derechos implícitos.

\begin{abstract}
Migration has accompanied human development forever. However, with the consolidation of borders and the nation state, human mobility has been restricted as a result of regulations mainly internal to each state. Settling in a territory other than the one of origin in search of new possibilities, which at first was an undisputed right, today is rather a concession of the destination state. The reflection proposed in this article aims to rescue the conception of the ius migrandi as a fundamental right inherent to the individual, who since its appearance has moved from one place to another in search of food, security, or just out of curiosity, always seeking its maximum development. Today, the right to free movement within the territory and the right to leave the state are recognized. However, this right to leave becomes illusory if it is not correlated with a right to enter another state. The right to migrate includes both rights, to emigrate and to immigrate, and it is configured within the theoretical framework of human rights as an implicit right, derived from human dignity and the right to free movement.
\end{abstract}

Keywords: right to migrate, ius migrandi, human mobility, free movement, fundamental rights, implicit rights. Abogado. Estudiante de Magíster en Derecho Constitucional con mención en Derecho Procesal Constitucional, Cecoch, Universidad de
Talca. Correo: varayam@gmail.com 


\section{Introducción}

La movilidad humana es un hecho que ha acompañado el desarrollo de la civilización desde siempre. De acuerdo con lo que señala la Organización Internacional para las Migraciones (OIM): "migración o el acto de migrar es el desplazamiento desde un territorio de un Estado hacia el territorio de otro Estado o dentro del mismo. Se refiere a cualquier movimiento de población, independientemente de su tamaño, composición o causas" (OIM y IPPDH, 2017, p. 20). Este concepto comprende migración forzada y migración voluntaria, migración permanente y temporal. Todas estas distinciones en la realidad pueden encontrarse en diversas combinaciones, lo que complejiza el asunto.

Si se reflexiona sobre el tema es relativamente fácil visualizar que el ser humano se mueve de un lugar a otro en busca de beneficios de algún tipo: económicos, sociales, por seguridad individual, entre otros. Este fenómeno se ha producido sin grandes restricciones desde la aparición del hombre hasta la consolidación del Estado nación. Lo que fue natural por prácticamente toda la existencia del ser humano, se ha vuelto un acto complejo y lleno de restricciones. Estas pesan sobre los no naturales de un Estado:

Se ha normalizado en muchas de nuestras democracias (supuestamente basadas en el reconocimiento indiscutible y fundamental del estado de Derecho y de los derechos humanos) un control administrativo y societal excepcional y constante sobre las personas migrantes que de ninguna manera sería tolerado por los nacionales (...) Se ha impuesto una naturalización de la discriminación de las personas migrantes que debe ser combatida y una de las armas con las que contamos son los derechos humanos. (Penchaszadeh, 2016, p. 270).

Un primer paso para comprender adecuadamente el fenómeno es visibilizar al migrante como persona (aunque parezca obvio) y, en cuanto tal, sujeto de derechos humanos, antes que individuo obligado para con el Estado. Quienes que se trasladan de un lugar a otro, antes que migrantes, son personas, aunque parece difícil notarlo para el derecho. En el intento por clasificar a cierto grupo de seres humanos bajo la categoría de "migrantes" se hace desaparecer su calidad de tal. Debe entonces primar un enfoque de derechos humanos. Esto no significa necesariamente centrar la discusión en los derechos humanos de los migrantes; a nuestro juicio, ello sería un retroceso a mediados del siglo pasado. En tanto personas, los migrantes son lo mismo que los nacionales de un país y no cabe, por tanto, argumentar que son titulares de derechos; estos no derivan de su vínculo con uno u otro territorio, sino de su condición humana. Lo que debe discutirse es si el derecho a migrar es un derecho humano.

Este trabajo pretende examinar el tema de la migración voluntaria y argumentar respecto a su calidad de derecho fundamental. Nuestra hipótesis es que el derecho a migrar no está correctamente comprendido por los instrumentos jurídicos vigentes ni menos por las políticas de movilidad humana de los distintos países. Es un derecho esencial derivado de la condición humana y con un contenido específico, autónomo. De ello surgen importantes consecuencias, principalmente las relacionadas con los límites que el Estado puede imponer al ejercicio de este derecho. Se usará el método dogmático e inductivo, para lo que se revisará doctrina reciente. Posteriormente se propondrá una argumentación para configurar el derecho.

El texto se divide en tres partes. La primera explica brevemente la migración como actividad humana y describe la regulación existente, las opiniones doctrinarias y expone lo que serían las razones del derecho del Estado a restringir la migración. La segunda parte reseña brevemente los derechos fundamentales, con especial énfasis en los derechos implícitos, que sirven de base para la tercera parte, que desarrolla nuestra tesis —el derecho a migrar es un derecho fundamental implícito-, explica su contenido y las consecuencias que se derivan de su reconocimiento. 


\section{Estado de la cuestión}

Las regulaciones migratorias, en términos generales, reconocen la libertad de circulación dentro del ámbito estatal y el derecho a salir y a regresar al país de origen. En el orden interno de los Estados, sus leyes migratorias establecen los requisitos de entrada y permanencia al interior del país, así como las sanciones frente a los incumplimientos. Al contrario de lo que podría pensarse, en el proceso de globalización "la eliminación de las barreras a la libre circulación de mercancías, servicios y capitales, así como el libre flujo de la información y la comunicación, no han (...) acompañado una eliminación o flexibilización de leyes migratorias" (Juste, 2019, p. 536). Así, el primer elemento común entre los instrumentos jurídicos internacionales y nacionales es la configuración de distintas situaciones migratorias: legal e ilegal, en tanto cumplan o no los requisitos que establece cada Estado. Esta distinción es universal, positivizada en todos los instrumentos jurídicos que se refieren al asunto. Del mismo modo en que las fronteras del Estado nación crean una distinción entre nacionales y extranjeros, los instrumentos jurídicos y sus requisitos crean una distinción entre migrantes en situación legal e ilegal, o regular e irregular.

El derecho a migrar o ius migrandi tiene antecedentes en Domingo de Soto (en Arcos, 2020, p. 286) y Francisco de Vitoria (1975), quien señalaba:

Los españoles tienen derecho a viajar y permanecer en aquellas provincias, mientras no causen daño, y esto no se lo pueden prohibir los bárbaros. Se prueba en primer lugar por el derecho de gentes, que es derecho natural o se deriva del derecho natural... En todas las naciones se tiene por inhumano el recibir y tratar mal a los huéspedes y peregrinos sin motivo especial alguno, y, por el contrario, se tiene por humano y cortés el portarse bien con ellos, a no ser que los extranjeros aparejaran daños a la nación. (p. 88).

Observa Arcos (2020) que la historia del pensamiento jurídico muestra que ni siquiera sería un derecho de primera generación, sino que es uno de los primeros derechos naturales formulados en la tradición liberal clásica: "si Vitoria configura el ius migrandi como un derecho universal derivándolo de otro derecho, el ius communicationis ac societatis, Locke lo enuncia como el corolario del nexo propiedad/trabajo y Kant hace del mismo el contenido del derecho de hospitalidad" (p. 287).

En Chile, la migración ha sido objeto del derecho desde los inicios de la República. En un principio las normas tuvieron por objeto atraer inmigración con el propósito de poblar el territorio y desarrollar ciertas actividades económicas (Aninat y Sierra, 2019, p. 33). Las primeras normas sobre el tema datan de 1824; en ellas se ofrecía garantías a extranjeros para establecerse en el país y dedicarse a la agricultura o a la industria. En 1854 la población migrante en Chile representaba al 1,36\% de la población (p. 34), pero luego de ingentes esfuerzos del Gobierno por atraer migración, principalmente europea, en 1907 la población extranjera equivalía al 4,14\% del total de la población en Chile (ibid.). Sin embargo, con el correr del siglo XX, en 1952 la población migrante era solo 1,6\% del total (p. 35). En 1953 se reguló la migración de forma más completa, pero con un fuerte énfasis en una migración dirigida (ibid.). Finalmente, en 1975 se dictó el Decreto Ley 1.094, que regula la materia hasta hoy, complementado por su reglamento vigente desde 1984.

No puede obviarse que el principal motivo para trasladarse de un lugar a otro es la mejora de las condiciones de vida:

El Informe sobre migraciones internacionales 2015 de la División de Población del Departamento de Asuntos Económicos y Sociales (ONU) señala que, en el periodo 2000-2015, las migraciones 
internacionales ascendieron a 71 millones de personas, de las cuales 57 millones tuvieron como destino países de altos ingresos (81\% del total). (Arce, 2018, p. 118).

Según el Banco Mundial, el límite inferior para considerar un país de ingreso alto se encuentra en USD 12.375 de PIB/cápita, a julio de 2019 (World Bank Data Team, 2019). En este marco, Chile es un país de ingresos altos y, en consecuencia, serio candidato a mantener un alto interés por establecerse en él.

\subsection{Opiniones doctrinarias respecto del derecho a migrar}

Respecto al derecho a migrar, no ha sido reconocido expresamente. Tampoco ha sido una conclusión de interpretación respecto de alguno de los instrumentos internacionales sobre derechos humanos (Arcos, 2020, p. 288). La OIM y la IPPDH señalan que

los instrumentos internacionales reconocen el derecho a salir de un Estado del cual se es nacional, pero (...) cabe preguntarse si existe un derecho a entrar a otro Estado del cual la persona no es nacional. Si no hay un derecho a entrar difícilmente pueda además hablarse de un derecho a migrar. (2016, p. 37).

García (2020) concuerda en que, no obstante las legislaciones de Argentina, Bolivia, Ecuador y Uruguay han hecho esfuerzos, falta el reconocimiento internacional al derecho humano de ingresar a un país distinto al de la nacionalidad (p. 125). Para Ferrajoli (2019), la tradición liberal siempre ha considerado el derecho a migrar como fundamental. Los hombres no pueden extenderse hasta el infinito, pues la tierra es finita y en consecuencia deben estar unos con otros, sin que nadie originariamente tenga más derecho que otro a estar en un determinado lugar de la tierra (p. 35). Indica que la visión actual de la migración es mayormente utilitaria, en tanto el migrante posee valor como mano de obra de bajo costo para los trabajos más pesados: "[es] un excelente negocio para los empresarios, un ahorro en los costos de toda formación de la fuerza laboral, excepto un ser humano titular de derechos igual que los ciudadanos" (p. 45). Observa además que las campañas contra los migrantes están vinculadas con la seguridad. Habría una abundancia de prejuicios y lugares comunes que fortalecen el miedo a la migración, teniendo como consecuencia un imaginario racista (p. 46).

Nieves Hernández (2014) coincide en que el derecho internacional no ha sido capaz de incorporar de forma plena la migración como un derecho internacional en los distintos instrumentos. Por ello es un hecho pacífico entre los positivistas que el derecho humano a migrar no existe como tal (p. 51). A pesar de las muchas opiniones en torno a que el derecho a migrar estaría incluido de una u otra forma en los instrumentos internacionales, el autor considera que no existe en el ámbito internacional, toda vez que la entrada, estancia y salida no se completan en los derechos enumerados internacionalmente (p. 55).

Por otro lado, contradice a autores como Pedro Ojeda, quien afirma que migrar es un derecho humano esencial, apoyándose en el artículo 13 de la DUDH, pero que acto seguido se refiere a los derechos de los migrantes y no al derecho a migrar (Nieves, 2014, p. 55). Analizando el artículo, indica que, si bien se establece el derecho a la libre circulación y a la elección del lugar de residencia, los circunscribe al interior del Estado; es una migración interna. La segunda parte señala que se puede salir de cualquier país, incluyendo el propio, y regresar al mismo, pero en ningún momento se contempla el derecho de entrar a cualquier país, que en opinión del autor es requisito indispensable para configurar el derecho a migrar. Entonces difícilmente puede hablarse del derecho humano a migrar a nivel internacional, más aún cuando aquellos instrumentos internacionales que se refieren al tema terminan por subordinarlo a las leyes internas de cada país (p. 56). Sostiene finalmente que, si bien no existe un derecho humano a migrar, a nivel internacional sí existen los derechos humanos de los migrantes (p. 60). 
Velasco (2016), en un interesante cuestionamiento de las fronteras, afirma que el derecho de las personas a circular libremente es un conjunto de paradojas. Para empezar, debiese ser absolutamente normal que la superficie inhabitada del planeta fuera de libre acceso para quien pueda acceder a ella, pues el planeta es propiedad común de lema de la humanidad, idea que ya había sido sugerida por Kant. Y si la tierra es un bien común, entonces el acceso a cualquier parte ella debiese estar universalmente garantizado (p. 43). La ocupación permanente de un territorio específico por parte de un grupo humano genera ciertos derechos, pero no puede distorsionar el más básico derecho de los individuos a interactuar con otros seres humanos, o permitir la restricción de acceso a otras personas. La posibilidad de decidir dónde vivir es un aspecto fundamental de la libertad humana (p. 44).

Díaz (2016) concuerda en que si se considera inmigrar como llegar a otro país para establecerse en él, no existe norma del derecho internacional que lo reconozca como derecho fundamental. Coincide en que solo se ha reconocido el derecho a emigrar, circular libremente dentro del Estado y retornar al país del cual se es nacional (p. 184). De este modo, observa una primacía de la soberanía del Estado por sobre el derecho de las personas a cambiar libremente su residencia de un Estado a otro (p. 186). Respecto de las causas de prohibición de ingreso y de expulsión, es de la opinión que la norma nacional confrontada con la internacional es acorde en la mayor parte de los casos (p. 191).

Domínguez (2016) señala que no existe un derecho a inmigrar propiamente tal, aunque a partir del reconocimiento del derecho a emigrar y a retornar al país de origen se pueden establecer ciertas condiciones mínimas de trato, respecto de los extranjeros que se presentan en frontera o que se hallan en el territorio del Estado (p. 191). Para Gutiérrez (2017) tampoco existe un derecho a migrar. Señala este autor que la inmigración en Chile ha sido aceptada por una cuestión de necesidad, no obstante, genera molestias en la ciudadanía producto de la llegada de extranjeros que tienen el propósito "franco y directo de delinquir" (p. 99).

\subsection{El derecho del Estado a restringir la migración}

Es de común aceptación que los países tienen facultades para restringir y regular el acceso de personas extranjeras a su territorio, expulsar aquellas que en ciertas circunstancias sean sancionadas y adoptar medidas para proteger la seguridad del Estado. Pero debe tenerse presente que todas estas facultades deben ser ejercidas con pleno respeto a los derechos humanos y a las normas de derecho internacional público que inciden en la materia. Surge así frecuentemente la duda de si el respetar ciertas disposiciones internacionales menoscaba la soberanía del Estado (CEPAL, 2008, p. 317). Una primera aproximación sugiere que los fenómenos de la globalización inducen a generar organizaciones e instrumentos jurídicos de carácter internacional para la resolución de conflictos, que de otro modo serían imposibles de afrontar por un Estado aislado. Este enfoque se contrapone con la opción predominante en los Gobiernos y en buena parte de la sociedad de los Estados receptores, que consideran los movimientos migratorios como un problema y no como un fenómeno o actividad humana permanente. De este modo, ante los argumentos a favor de la migración y la libre circulación a través de las fronteras, se esgrime siempre la tradicional defensa de la soberanía nacional (Nieves, 2014, p. 52), generando posiciones bastante rígidas en torno a ella. No se observa con frecuencia una confrontación entre dicha soberanía y el derecho a migrar o, al menos, los derechos de los migrantes.

La soberanía es un concepto que ha venido mutando conforme el paso del tiempo. Sin ser materia de este estudio, convengamos que es una manifestación del poder en virtud de la cual un Estado se da sus propias reglas y se plantea en condición de igualdad frente a otro. Señala Díaz (2020) que 
si bien el Derecho internacional reconoce la soberanía de cada estado a regular la migración en su territorio, su legislación nacional debe ser conforme a las normas internacionales sobre derechos humanos, pues si los estados son parte del sistema de protección de los derechos humanos y han dado su consentimiento en obligarse, deben ser respetuosos de los principios de observancia de los tratados. (p. 69).

Sin embargo, creemos que el derecho internacional, en vez de cautelar el derecho a migrar, ha preferido ser deferente con el derecho a restringir la migración por parte de los Estados (Aguelo y Granero, 2017, p. 73$)^{2}$.

Otra razón esgrimida para limitar la inmigración son los recursos. Aun cuando el ejercicio del ius migrandi no debe significar un empobrecimiento para las partes, la lógica exige considerar que este empobrecimiento no ha de comprenderse en exclusivos términos económicos.

La comunicabilidad y sociabilidad entre las personas reporta también beneficios a veces difícilmente cuantificables a corto plazo, que redundan en el enriquecimiento cultural, social o personal de las sociedades receptoras y de los migrantes. Estamos ante una materia que, en situaciones de crisis económicas, sale a la luz pública, no siempre desprovista de tintes xenófobos. (Aguelo y Granero, 2017 , p. 89).

En nuestro país, Aninat y Sierra (2019) señalan que una regulación correcta debe perseguir tres objetivos: "lograr una asimilación económica adecuada de los inmigrantes, velar por una migración ordenada y regular, y tratar a los inmigrantes como los sujetos de derechos humanos que son” (p. 36). Si bien compartimos algunos de sus planteamientos, no deja de ser llamativo el tratar a los migrantes como "sujetos de derechos humanos". Ello da cuenta del enfoque de la Ley de Extranjería nacional, aunque creemos que este no ha variado con el paso del tiempo.

Recientemente se ha publicado un libro escrito por el actual director del Departamento de Extranjería y Migraciones, titulado Gestión de la migración en el s. XXI. El hecho de hablar de "gestión" de personas ya revela una cierta postura frente al tema. En el capítulo tercero explica las medidas implementadas por el actual Gobierno en materia migratoria y detalla algunos lineamientos estratégicos, destinados a eliminar riesgos para la materialización del proyecto de vida en el país (Bellolio y Valdés, 2020, p. 86). Identifica como riesgos: la presencia de migrantes en situación irregular, la polarización política derivada del tema migratorio y la socavación de la institucionalidad, al "permitir que decenas de miles de extranjeros entraran al país declarando un objetivo distinto al real (turistas en vez de migrantes) era inconsistente con pedirle a esos mismos extranjeros que cumplieran con la ley en general" (p. 87).

Finalmente, el libro indica que en un escenario hipotético en que el flujo migratorio sea bajo, será necesario tomar medidas para revertir la situación y fomentar la inmigración. En una lógica —en nuestra opiniónabiertamente utilitarista, señala que "podría darse esta situación si existe necesidad de ciertos tipos de profesionales o técnicos que no pueden ser suplidas por nacionales" (Bellolio y Valdés, 2020, p. 130). Todo ello permite inferir que el enfoque de derechos no está presente en la autoridad migratoria. Esta visión

\footnotetext{
La DUDH marcó la desaparición del ius migrandi de los tratados internacionales, pues lo restringió solo a la salida y lo condicionó al ejercicio de la soberanía estatal. Sin el correlativo derecho a entrar en otro Estado, el derecho a migrar queda prácticamente vaciado de contenido. No obstante lo evidente y obvio de aquello, no se explicitó en la declaración. Todos los posteriores instrumentos internacionales reconocen el derecho del Estado a restringir y regular la entrada de extranjeros. Incluso vincularon el derecho a permanecer en el Estado a condición de hallarse legalmente en él, hipótesis que no estaba presente en la declaración. La CTM establece estatutos diferenciados según la situación migratoria de la persona. Estimamos que todo ello solo contribuye a reforzar la idea de control de policía por parte del Estado, sin invitar a desarrollar una política migratoria. En este caso es el propio instrumento el que discrimina entre migrante en situación regular e irregular.
} 
de la migración como un asunto de seguridad es, a nuestro juicio, violatoria de derechos humanos, pues caracteriza a las personas como "amenazas que deben ser repelidas o neutralizadas" (Morales y Sanromán, 2016, p. 363). Son solo consideradas como un recurso deseable en la medida que signifiquen un aporte a las necesidades de mano de obra especializada.

Compartimos con García (2016) la crítica respecto a que es el mismo Estado el que crea categorías respecto de las personas, las separa en nacionales y extranjeros, quienes tienen un estatuto jurídico distinto que es "creado, recreado y administrado por el estado". Señala muy acertadamente que "a diferencia de otras situaciones de desigualdad (edad, género, etc.), la desigualdad de la persona extranjera es inaugurada y sostenida desde el estado" (p. 121). Esta categorización de las personas establece diversas vinculaciones entre ellas y el Estado receptor, que increíblemente no son apreciadas como discriminatorias en términos de derechos humanos. En virtud de estas categorías se "valida acciones que no serían permitidas si se tratara de nacionales, como negar el acceso a la salud, disponer extendidas situaciones de privación de la libertad sin delito, organizar un aparato de criminalización por el solo hecho de no tener papeles" (p. 121).

Mientras en otros casos la ley busca equilibrar situaciones de discriminación entre distintos grupos de la sociedad - como, por ejemplo, estableciendo una ley de cuotas-, en este caso es la propia norma la que crea la discriminación, generando, como ya dijimos, estatutos diferenciados en virtud de estas categorías de personas creadas. Agregamos a lo anterior que es contradictorio que estas mismas categorías que se critican estén contenidas en instrumentos internacionales de derechos humanos.

\section{Los derechos fundamentales}

En términos generales, la doctrina de los derechos humanos se construye en base a dos grandes corrientes: el iusnaturalismo y el iuspositivismo. En virtud del primero, los derechos humanos pertenecen al ser humano por su condición de tal y no dependen del ordenamiento, que solo se limita a reconocerlos. Para la segunda corriente los derechos humanos existen solo si están reconocidos en un instrumento jurídico. Nuestra hipótesis se enmarca preliminarmente en la primera de estas corrientes.

\subsection{Derechos fundamentales y sus fuentes}

Como concepto de derecho fundamental utilizaremos el propuesto por Nogueira (2007):

son el conjunto de facultades e instituciones que, concretan las exigencias de la libertad, la igualdad y la seguridad humanas en cuanto expresión de la dignidad de los seres humanos — considerados tanto en su aspecto individual como comunitario-, en un contexto histórico determinado, las cuales deben ser aseguradas, respetadas, promovidas y garantizadas por los ordenamientos jurídicos a nivel nacional, supranacional e internacional, formando un verdadero subsistema dentro de estos. (p. 253).

Los derechos fundamentales, consagrados en la Constitución, son por tanto normas supremas del Estado y contribuyen a determinar su orden jurídico. Son distintos de las normas ordinarias, no solo por su jerarquía, sino por su contenido, pues arrancan de la dignidad humana (Magallanes, 2016, p. 242). En este sentido, tienen una estructura de principios y se caracterizan por su universalidad, su carácter fundamental, su abstracción, su moralidad y su prioridad (Alexy, citado en Chávez-Fernández y Ríos, 2019, p. 180). En una concepción más positiva, el elemento que distingue a estos derechos es su materialización constitucional. De ahí su dimensión tanto de derecho subjetivo como de valor y principio constitucional que se traduce en mandato de actuación para los poderes constituidos (Corchete, 2007, p. 540). 
Como características, cabe señalar que los derechos humanos son universales, pues no distinguen entre las personas. Son inalienables e irrenunciables, ya que nadie puede ser despojado de ellos; y son indivisibles, porque no importa su naturaleza; todos se refieren a la dignidad de las personas. Todos tienen la misma importancia y no pueden ser jerarquizados, pues son interdependientes e interrelacionados (OIM y IPPDH, 2017, p. 17).

Díez-Picazo (2008) distingue entre una concepción formal y una concepción material de los derechos fundamentales. Para la primera "son derechos fundamentales aquellos que están declarados en normas constitucionales o al menos en normas de rango supra legal; lo característico de los derechos en este caso es su resistencia frente a la ley" (p. 39). La concepción material, por su parte, establece que los "derechos fundamentales son aquellos que en un ordenamiento dado se reconocen a todas las personas por el mero hecho de serlo. Lo verdaderamente peculiar de los derechos es su contenido" (p. 38). Así, en una concepción material que compartimos, Nogueira (2007) señala que en

el ámbito americano, los derechos fundamentales no son únicamente los asegurados expresamente en el texto constitucional, ya que además se encuentran los derechos implícitos y los derechos contenidos en tratados internacionales ratificados y vigentes, además de las otras fuentes del derecho internacional como el ius cogens y el derecho consuetudinario internacional. (p. 253).

Este conjunto de fuentes es el que Nogueira (2015) denomina como "bloque constitucional de derechos" (p. 311-315). Ahora bien, no todos los derechos reconocidos internacionalmente son necesariamente derechos humanos. Los derechos aceptados como fundamentales por la Constitución comprenden dos clases de derechos: los que ella misma regula y los reconocidos en los pactos internacionales sobre derechos humanos, lo que supone una armonía entre el derecho constitucional y el internacional (Magallanes, 2016, p. 239). Así, los derechos implícitos están, a nuestro juicio, incluidos por vía del artículo 29 c) de la $\mathrm{CADH}$.

Como explica Nogueira (2007), la Constitución manifiesta una protección genérica a la existencia de derechos esenciales, lo que genera un catálogo de derechos abierto, por cuanto "el constituyente reconoce sus eventuales limitaciones y está consciente del desarrollo progresivo de los derechos y garantías acorde a la naturaleza y necesidades esenciales del ser humano" (p. 250). La característica de catálogo abierto proviene además del reenvío que hace el inciso $2^{\circ}$ del artículo 5 a los tratados internacionales de derechos humanos ratificados por Chile y que se encuentren vigentes, entre ellos, la $\mathrm{CADH}$.

\subsection{Derechos implícitos}

Las constituciones, así como los tratados internacionales de derechos humanos, contienen un listado de derechos enunciados, ya sea de carácter general — como el caso de la $\mathrm{CADH}$ - o con un enfoque más específico, como la CTM. Pero, además, muchos de estos instrumentos contienen cláusulas que permiten hacer reenvíos fuera de sus textos, para de este modo dejar a salvo otros derechos no contenidos en el articulado (Bidart, 2002, p. 257).

De acuerdo con lo expuesto por Gross (2000) a partir de la naturaleza de los derechos humanos, una parte de la doctrina ha efectuado una interpretación evolutiva de algunos preceptos, dando cabida de este modo a derechos no enunciados en los instrumentos internacionales. En el contexto americano, el artículo 29 c) de la CADH resolvería este asunto al indicar que ninguna disposición de la convención puede interpretarse en el sentido de excluir otros derechos y garantías inherentes al ser humano o que se derivan de la forma democrática representativa de gobierno (p. 168). Seńala el autor que la presencia de 
una norma alusiva a los derechos no enunciados o no enumerados en varias constituciones americanas, informa una característica del derecho constitucional americano (p. 145).

Aceptar la presencia de estos derechos implícitos permite concluir que no es necesario que un derecho fundamental esté expresamente mencionado en el catálogo constitucional o en algún instrumento de derecho convencional; puede deducirse de "valores, principios, fines y razones históricas que alimentan el derecho positivo constitucional e internacional” (Nogueira, 2007, p. 254).

Para Bidart (2002), la CADH contiene en las reglas para su interpretación del artículo 29, tres pautas que considera alusivas a derechos implícitos: los incisos b), c) y d):

ninguna disposición de la presente Convención puede ser interpretada en el sentido de: b) limitar el goce y ejercicio de cualquier derecho o libertad que pueda estar reconocido de acuerdo con las leyes de cualquiera de los Estados partes o de acuerdo con otra convención en que sea parte uno de dichos Estados; c) excluir otros derechos y garantías que son inherentes al ser humano o que se derivan de la forma democrática representativa de gobierno, y d) excluir o limitar el efecto que puedan producir la Declaración Americana de Derechos y Deberes del Hombre y otros actos internacionales de la misma naturaleza.

Agrega que, del mismo modo, el artículo 5.2 del PIDCP reconoce la existencia de derechos fuera de los contemplados en el mismo instrumento (p. 228). En definitiva, estos derechos — del modo que los contemplan las cláusulas constitucionales o convencionales - reenvían en último término a la dignidad humana y a los derechos esenciales que emanan de ella, asunto que "trasciende la normatividad y el voluntarismo político" (p. 260). En consecuencia, los derechos implícitos son derechos humanos perfectamente vigentes, válidos y aplicables, que se nutren de distintos órdenes jurídicos (Aguilar, 2010, p. 68).

En el caso de Chile es interesante mencionar que el anteproyecto de la nueva Constitución contempló originalmente un artículo 28, que señalaba: "la Constitución asegura el respeto a todo derecho inherente a la persona humana, aunque no esté expresamente contemplado en su texto". Comenta Varas (1993) que en la sesión 414, la comisión Ortúzar suprimió el precepto en virtud de una proposición del comisionado Guzmán; argumentó que dicho artículo ya estaba considerado en el artículo 5, "de manera que su consagración adicional podría ser fuente de inconvenientes" (p. 725)3.

Es indudable que la construcción de un derecho implícito es una labor de la doctrina, pero es especialmente relevante por parte de la jurisprudencia, que es en definitiva la que decide la aplicación del derecho. En algunas ocasiones se infiere un derecho implícito de otro derecho expresamente conferido que lo presupone; en otras, el juez debe vincular varios preceptos de derechos humanos, con tal de darles sentido y cumplir con el objetivo de propender a la mayor protección posible de la persona y su dignidad. Con todo, para Guastini (2011) "es una idea generalizada en la cultura jurídica contemporánea que el sistema

\footnotetext{
Agrega Varas que los comisionados Ortúzar y Bertelsen estuvieron de acuerdo en que era redundante y ya contenidos en el capítulo de las bases de la institucionalidad. El informe remitido por la comisión al gobernante de facto seńalaba que "había contemplado una norma que aseguraba el respeto a todo derecho inherente a la persona humana, aunque no esté expresamente contemplado en su texto”. Concluye Varas, acertadamente a nuestro juicio, que "en virtud de lo anterior hay que entender que para la Comisión de estudio el inciso segundo del artículo cinco de su anteproyecto que establece: El ejercicio de la soberanía reconoce como límite los derechos que emanan de la naturaleza humana, debe interpretarse necesariamente en el sentido de que la Constitución asegura el respeto a todo derecho inherente a la persona humana aunque no esté expresamente contemplado en su texto" (1993, p. 726).
} 
jurídico incluye no solamente los derechos expresamente conferidos, sino también aquellos derechos implícitos que son condición necesaria para el ejercicio de los primeros" (p. 2) .

En contra de la existencia de derechos implícitos se ha manifestado Candia (2015b), quien ha sistematizado la forma en que la Corte IDH los ha argumentado. En su opinión, la Corte parte de la base que los preceptos de la Convención deben ser interpretados en conformidad a sus disposiciones. Luego alude a una norma cuyo texto es "vago e indeterminado". La Corte indica que dicha norma exige la adopción de un estándar cuyo contenido es conceptualizado como un derecho elaborado en virtud de una deducción lógica, proceso que conduce a un resultado necesario. La consecuencia que observa es "el reconocimiento de derechos no contemplados en el texto y la incorporación indirecta de derechos y estándares de juicio provenientes de otros tratados internacionales de derechos humanos" (p. 876). Continúa señalando que la Corte afirma invariablemente que la formulación de estos derechos implícitos corresponde a un ejercicio de interpretación y no de creación jurisprudencial. Presenta una postura crítica al respecto, pues advierte que en virtud de este ejercicio tanto la Corte IDH como las Cortes de cada Estado que lo realicen, más que determinar un derecho implícito, lo que hacen es reformar la Constitución sin reconocerlo, pues crean derecho. Por ello, estas cortes se refieren a los instrumentos que interpretan como textos vivos, cuya interpretación es evolutiva (p. 879). Sintetiza su planteamiento señalando que la Corte IDH a través de su interpretación crea derechos, vulnerando el principio de legalidad al no actuar conforme a las potestades que le fueron entregadas (p. 898).

Respecto de la idea de legalidad, agrega el autor que, en el derecho interno, la Constitución establece quórums supramayoritarios para la modificación o inclusión de derechos fundamentales en el capítulo correspondiente; ello con el objetivo de propiciar el mayor consenso político posible. Así, la idea de los derechos implícitos, que en su opinión son nuevos derechos de construcción jurisprudencial, burlan el mecanismo constitucional (Candia, 2015a, p. 520). Rebate además la idea de que el Tribunal Constitucional habría reconocido la existencia de tales derechos. El Rol 1.340, que ha servido de base en este sentido, tuvo un voto particular del ministro Bertelsen, cuya opinión es la que se ha expuesto en las sentencias Rol 1.537, 1.563 y 1.656. Lo que en un principio se argumentó a partir del reconocimiento de derecho implícito del derecho a la identidad, posteriormente se basó en el derecho de igualdad ante la ley. En su interpretación, el tribunal abandonó la tesis de los derechos implícitos, pues comprendió que puede significar "en manos de magistrados sin disciplina institucional una grave complicación para el modelo constitucional chileno" (p. 520).

También en contra de los derechos implícitos se ubica Aldunate (2008), quien señala que la opinión mayoritaria de la doctrina considera que los derechos contenidos en el artículo 19 no son taxativos y contempla por tanto la posibilidad de que existan derechos fundamentales no consagrados en la Constitución. A su entender, esta posición se basa en el entendido de que los derechos fundamentales son una demanda hacia el sistema jurídico y por tanto no requerirían formulación positiva para su defensa y cautela. Critica esta posición, pues sostiene que ello

implica investir a los órganos jurisdiccionales no sólo con una facultad y deber de tutela respecto a entidades innominadas, sino que, en el caso de la jurisdicción constitucional, dotarla de facultades para alzarse en contra de la actuación legislativa, sobre la base de proposiciones iusfundamentales sin respaldo constitucional positivo. (p. 345).

No obstante estar de acuerdo con la existencia de los derechos implícitos, expone con claridad los inconvenientes que se presentan en ellos. Se ha preferido en este trabajo privilegiar las opiniones en contra, provenientes de la doctrina nacional. El desarrollo de puede consultarse en Guastini, 2011, pp. 4-5. 
En el mismo sentido se ha manifestado Contreras (2011), para quien el hecho de que el capítulo tercero no sea taxativo no implica necesariamente la existencia de derechos implícitos (p. 174). Para él, el ya citado artículo 29 de la CADH "no permite la atribución de nuevos derechos ni faculta un evolucionismo en materia de interpretación sino que busca limitar la discrecionalidad de la hermenéutica de las disposiciones de derechos humanos" (p. 175).

Expuestas algunas opiniones a favor y en contra de la existencia de derechos implícitos, adherimos a lo expuesto por Nogueira, en cuanto forman parte del bloque constitucional de derechos. Por lo de demás, tal fue la intención del constituyente, de acuerdo con lo reseñado por Varas respecto de las actas de la Comisión Ortúzar. Más importante aún es la interpretación que ha hecho la Corte IDH respecto al texto de la $\mathrm{CADH}$, vinculante para el Estado.

\section{El derecho a migrar o ius migrandi}

No es opinión predominante que migrar sea un derecho esencial del ser humano. El Subsecretario del Interior indicaba en 2018 la postura del Gobierno, a propósito del Pacto Mundial sobre Migración: "nuestra posición es clara. Nosotros decimos que la migración no es un derecho humano... si lo fuera, entonces estamos en un mundo sin fronteras" (Minay y Muñoz, 2018, s/p).

La migración constituye un fenómeno que puede dividirse en tres momentos: la salida de un Estado, la entrada a otro con ánimo de permanencia y eventualmente el regreso al país de origen. Dependiendo de la dirección puede hablarse de emigración, inmigración o transmigración; incluso, dependiendo del modo en que se haga, puede hacerse referencia a la migración documentada o indocumentada. A pesar de ser todos estos tipos manifestaciones del mismo fenómeno, tienen especificidades propias (Nieves, 2014, p. 54)

Otra clasificación propuesta por Juste (2019) distingue en base a las motivaciones, dividiendo entre migrantes forzados (que huyen de la persecución y de los conflictos armados), migrantes económicos (que huyen de la pobreza y la carencia de expectativas de progreso) y migrantes ecológicos (que huyen de los desastres naturales, de la degradación ambiental y de los efectos adversos de la desertificación y del cambio climático). También hace una distinción entre los migrantes regulares, que han sido admitidos legalmente en el Estado de recepción, y los migrantes irregulares o ilegales, que han entrado y permanecen en el territorio contraviniendo las leyes del Estado (p. 536). Como hemos visto anteriormente, la protección del derecho se limita al acto de circular libremente dentro del territorio del Estado, a abandonarlo, pero no a ingresar a otro Estado (Arcos, 2020, p. 287; Nieves, 2014, p. 58).

A diferencia de lo sostenido por Vitoria hace cinco siglos, la legislación internacional reconoce al Estado destino de la migración un derecho irrestricto a decidir o a aceptar el ingreso de un extranjero. Coincidimos con Juste (2019) en que de este modo se configura un derecho absurdo; si todos los Estados disponen del derecho a rechazar extranjeros en sus territorios y un emigrante no es admitido en ninguno de ellos, ¿¿ónde

\footnotetext{
La OIM y la IPPDH (2017) distinguen las etapas migratorias siguientes: "Emigración: es el acto de salir de un Estado con el propósito de asentarse en otro; Tránsito: escala o pase por un país intermedio en el viaje hacia el país de destino; Ingreso al país de destino: corresponde a la entrada de un extranjero al país de destino de la migración, ya sea de manera regular o irregular; Permanencia: etapa en la que la persona se encuentra viviendo en otro país en calidad de migrante, ya sea de manera regular o irregular; Retorno: es el acto o proceso de regreso al país de origen. Este retorno puede ser voluntario o forzoso y puede también ser asistido o espontáneo" (p. 20).
} 
puede establecerse? (p. 540) ${ }^{6}$. Si se admite el derecho a emigrar, la respuesta no puede ser "en su país de origen". Así vemos situaciones dramáticas en el caso de migrantes rescatados en altamar, cuyo desembarco en la costa se enfrenta a menudo con el rechazo del Estado costero (Nieves, 2014, p. 58). Una persona que ejerciendo su derecho a salir de un Estado se encuentra en la frontera de otro sin poder traspasarla, ve negado el ejercicio de su derecho. El acceso verdadero a los derechos humanos depende entonces de la ciudadanía, una categoría previa que no es universal, sino que está restringida a una jurisdicción nacional: "lo declarado como universal se da únicamente bajo la condición no escrita de pertenecer a unos determinados colectivos en particular" (Straehle, 2018, p. 69).

\subsection{La dignidad humana y la libre circulación como antecedentes del derecho a migrar}

\subsubsection{La dignidad humana}

En el derecho actual es mayoritaria la posición que reconoce a la dignidad humana como origen de los derechos fundamentales. Sin embargo, su concepto admite muchas lecturas distintas, como señala Aldunate (2008). El autor infiere que los elementos presentes en toda noción de dignidad son

a) La noción de individuo (...); b) Las facultades inherentes al género humano, vinculadas a las posibilidades de desarrollo individual, que son su racionalidad y su libertad; c) El término dignidad se entiende predicado de un individuo humano frente a otros de su misma especie, como status o condición a ser reconocido por otros seres humanos. (pp. 98-99).

Nogueira (2015) conceptualiza la noción de dignidad, tomando como base a Sarlet:

cualidad intrínseca y distintiva reconocida a todo individuo que lo hace merecedor del mismo respeto y consideración por parte del estado y de la comunidad, implicando, en este sentido, un complejo de derechos y deberes fundamentales que aseguran a la persona tanto contra todo y cualquier acto de cuño degradante o deshumanizado, como garantizar las condiciones existenciales mínimas para una vida saludable, además de propiciar y promover su participación activa y corresponsable en los destinos de la propia existencia y de la vida en comunión con los demás seres humanos, mediante el debido respeto a los demás seres que integran la red de la vida. (p. 303).

Consecuencia de lo anterior es que la persona es un fin en sí misma y nunca un medio o un instrumento. Por lo tanto, aludir a la dignidad humana como fundamento de los derechos humanos significa acudir a la esencia del ser humano. Se han de satisfacer sus necesidades de modo tal de lograr su máxima realización y desarrollo (Castillo, 2008, p. 41).

En opinión de Nogueira (2007), la cual compartimos, la dignidad humana presente en el primer artículo de la Constitución es

un enunciado constitucional de eficacia directa y de aplicabilidad inmediata, teniendo un efecto anulatorio o invalidatorio de toda norma que contravenga o ignore dicha dignidad. El valor y principio jurídico de la dignidad humana genera un efecto de irradiación se desarrolla sobre los otros principios e instituciones constitucionales. (p. 247).

Citando a Scovazzi, Tullio (2016): "Il respingimento di un drama ummano collettivo e le sue conseguenze", en Antonucci, Amedeo; Papanicolopulu, Irini y Scovazzi, Tullio (coords.), L’immigrazione irregolare via mare nella giurisprudenza italiana e nell'esperienza europea (Turín, Giappichelli), p. 66. 
Agregamos que este efecto de irradiación permite vincularla con otros principios y derechos, con el objetivo de materializar las condiciones necesarias para la máxima realización espiritual y material de las personas. Conviene enfatizar que el Tribunal Constitucional

encuentra en las nociones de dignidad (artículo 1, CPR), naturaleza humana (artículo 5, inciso segundo, CPR) y los derechos constitucionales (artículo 19, CPR) una vinculación que los constituye como principios y valores básicos de fuerza obligatoria que impregnan toda la Constitución de una finalidad humanista (Cons 30 rol 943). (Chávez-Fernández y Ríos, 2019, p. 185).

A nuestro juicio, ello permite inferir una interpretación finalista y evolutiva de la carta, presupuesto fundamental para sostener la vinculación con la libre circulación tratada a continuación.

\subsubsection{El derecho a la libre circulación}

El derecho a la libre circulación, en términos amplios, es referido tanto al territorio del Estado como al territorio más allá de sus fronteras. Para nuestro estudio, el énfasis está puesto en lo segundo. El derecho está contenido en el artículo 19, No 7, letra a) de la Constitución y determina el contenido de la libertad ambulatoria:

Toda persona tiene derecho a residir y a permanecer en cualquier lugar de la República, trasladarse de uno a otro y entrar y salir de su territorio, a condición de que se guarden las normas establecidas en la ley y salvo siempre el perjuicio de terceros.

La disposición es muy similar a la contenida en la $\mathrm{CADH}$, artículo 22, y en el PIDCP, artículo 12, números 1 y 2 , ya transcritos anteriormente. Conceptualmente

la libertad ambulatoria o de circulación es aquel derecho que permita a la persona trasladarse sin obstáculos por el territorio nacional pudiendo asentarse donde estime conveniente, como asimismo, entrar y salir libremente del país, pudiendo expatriarse si lo considera adecuado. (Nogueira, 2002, p. 163).

Así las cosas, el derecho a salir de cualquier país, incluido el propio, y de regresar a él está reconocido como un derecho de todas las personas (Juste, 2019, p. 537). En el ámbito interno del Estado no es cuestionado que las personas cambien de residencia. Sin embargo, las mismas razones que pueden motivar este desplazamiento interno son las que probablemente motivan la migración internacional (Arcos, 2020 , p. 290). En este caso las posibilidades de materializarlo son inferiores, debido a las restricciones impuestas, de modo que estas posibilidades se confrontan con las restricciones para la migración. No solo eso: la experiencia y la propia legislación de extranjería muestran que la migración es más o menos fácil dependiendo de algunas características de la persona. Dado que gran parte de las leyes migratorias aluden a criterios económicos de utilidad, en la práctica la migración de un profesional es más fácil que la de una persona sin estudios; la migración de un empresario es mucho más fácil que la de un migrante pobre; y la de un hombre es más fácil que la de una mujer y además menos peligrosa.

En palabras de Morales (2016), estos derechos "son efectivos en tanto las personas reúnen requisitos, por ejemplo una nacionalidad que no genere temor, desconfianza o miedo, de lo contrario los migrantes pueden llegar a constituir un peligro biológico para la sociedad de acogida" (p. 222). Un segundo requisito es de índole económico, pues el migrante debe contar con recursos suficientes tales para que no sea percibido como una amenaza al empleo o a la seguridad pública (p. 223). Estas prerrogativas de selección de las personas que pueden acceder al territorio son facultades de las que aparentemente los Estados no 
son proclives a desprenderse. Esto explica el reconocimiento parcial del derecho a migrar y la absurda consagración de la emigración como derecho y no de la inmigración que queda en manos de las políticas nacionales migratorias y de fronteras, y por ende condicionado a los intereses de cada Estado (Arce, 2018, p. 126).

Una interesante interpretación —un tanto disidente de lo expuesto—es sostenida por Díaz (2016), quien indica que

no obstante la falta de reconocimiento expreso de un derecho a la inmigración en normas internacionales, nuestra Carta Fundamental sí consagra el derecho de todo extranjero a entrar libremente a nuestro país, pues el artículo 19 No 7 letra a) asegura a todas las personas, sin distinciones, el derecho de circulación y de residencia, y existe un mandato genérico de regulación normativa para el ejercicio del derecho, pero no para su impedimento o prohibición, por consiguiente, se ha interpretado, tanto por la doctrina como por la jurisprudencia, que la Constitución establece una regla de admisión general de extranjeros, lo que implica que en Chile el derecho de emigrar que tiene todo extranjero se correlaciona con su derecho de inmigración. (p. 187).

Creemos ver en esta interpretación un ejercicio similar al que requiere la determinación de un derecho implícito. No obstante, la autora sostiene la existencia de un derecho a inmigrar y nuestra hipótesis difiere, por cuanto sostenemos la existencia de un derecho a migrar, que contiene, entre otros, el derecho a ingresar a un país distinto al de origen con ánimo de residir en él.

\subsection{El derecho a migrar como derecho implícito}

Se ha expuesto ya que la dignidad humana es fuente de los derechos fundamentales. Su respeto y promoción impone como deber y obligación al Estado el generar las condiciones para la mayor realización espiritual y material posible; en otras palabras, la persona humana es el centro y fin del Estado. Por otra parte, se ha descrito el derecho a la libre circulación, en los términos en que es reconocido tanto en instrumentos internacionales como en la propia Constitución. Dicho esto, la libre circulación en tanto facultad para salir de un Estado debe necesariamente complementarse con el derecho de ingresar a otro. De lo contrario el derecho a salir del país de origen se torna absurdo e inservible. Independientemente del motivo que lleva a una persona a decidir salir de su país, en todo caso corresponderá a un intento por desarrollarse en tanto persona. Si aceptamos lo argumentado respecto de la dignidad como fuente de derechos, no queda más que deducir que el derecho a inmigrar es una condición necesaria e imprescindible para la materialización del derecho a emigrar y de la naturaleza humana del migrante.

En el mismo sentido, Aguerre (2018) sostiene que

de la combinación de los derechos reconocidos en los documentos internacionales jurídicamente vinculantes puede derivarse en buena lógica que si todo ser humano tiene derechos dentro de un Estado, y también tiene derecho a ausentarse de dicho Estado, en tanto el mundo está conformado políticamente por diversos Estados, se sigue que tiene también el derecho a hacer ingreso en otros Estados diferentes. De esta argumentación se deriva que el derecho humano a migrar tiene fundamento en los tratados internacionales de derechos humanos, y por tal motivo los Estados miembros deberían adoptar medidas que permitan el libre movimiento y asentamiento de personas en sus territorios. (p. 78).

En todo caso, un "aspecto que añade complejidad al debate en torno a la inclusión del ius migrandi entre los derechos humanos es que los partidarios y críticos de esta posibilidad parten de concepciones diferentes de los derechos humanos" (Arcos, 2020, p. 290), en especial en lo referente a la existencia de derechos 
implícitos, cuestión no pacífica en la doctrina, como ya se expuso. Sin embargo, aceptando que es un fenómeno inherente al ser humano, "que siempre ha estado y estará presente en el escenario internacional y que en la historia de la humanidad se ha constituido como una regla y no como una excepción" (Nieves, 2014, p. 51), gran parte del camino se encuentra recorrido.

\subsubsection{Concepto y contenido del derecho a migrar}

El derecho a migrar puede considerarse en un sentido amplio, general, relativo al plan y proyecto de vida de una persona. En un sentido más acotado, puede referirse solamente a la movilidad: salir, transitar, ingresar, permanecer, volver. De acuerdo con la OIM y la IPPDH (2016), un contenido posible de este derecho incluye el derecho a no salir (no migrar), a un tránsito seguro, a ingresar a un Estado, a un estatus migratorio regular, a la libre circulación y residencia, y a un egreso consentido que limite la expulsión (p. 38).

Una propuesta de concepto es la siguiente: el derecho a migrar es aquel derecho fundamental en virtud del cual toda persona tiene derecho a emigrar de un Estado de origen —en un tránsito seguro- a otro Estado receptor, al cual puede ingresar de forma regular para establecerse en él por el tiempo que requiera. Tiene derecho además a salir del Estado receptor cuando lo estime conveniente, ya sea para volver al Estado de origen como para emigrar hacia otro. Tiene el deber y el derecho de integrarse en la sociedad receptora sin discriminación de ningún tipo. El ejercicio de este derecho a migrar supone el respeto a la legislación internacional y nacional que regule la movilidad humana, la que en ningún caso podrá restringirla al extremo de hacer impracticable el ejercicio del derecho.

A partir del concepto propuesto parece evidente que el núcleo del derecho, el contenido esencial del mismo, está conformado por el derecho a emigrar, el derecho al tránsito seguro, el derecho a inmigrar, el derecho a establecerse en el Estado de destino y el derecho a integrarse en la sociedad.

Por su parte, Chueca y Aguelo (2013) señalan que

el derecho a no migrar, el derecho a migrar, el derecho a establecerse pacíficamente y el derecho a retornar (...) se enmarcan en la libertad de movimiento de las personas; y que su (...) reconocimiento (...) permite cerrar el ciclo migratorio; algunas personas no lo cierran nunca, otras lo cierran en algún momento de su existencia. (p. 7).

Para los autores, el derecho a no migrar impone al Estado de origen el deber de generar condiciones de vida dignas que eviten la salida masiva de sus habitantes. El derecho a emigrar ya ha sido tratado profusamente, así que iremos con el derecho al tránsito seguro. Este implica que los Estados deben facilitar la circulación a través de sus fronteras. Se debe evitar la exposición indebida a factores de riesgo de los migrantes, que por lo general son un grupo vulnerable.

El derecho a inmigrar, por su parte, "supone que cualquier persona debe poder circular de forma voluntaria y libre por todo el planeta" (Chueca y Aguelo, 2013, p. 9). Su contenido no se reduce a la prohibición de impedir la movilidad física a través de las fronteras; incluye el derecho a entrar en los Estados extranjeros que se desee, tanto para visitas breves como para residir de forma permanente (Arcos, 2020, p. 289).

Respecto al derecho a establecerse en el Estado de destino, se establece un deber para el Estado receptor de permitir la residencia del migrante, sin que ello implique menoscabo en su dignidad, evitando desde luego un estatuto jurídico diferenciado arbitrariamente. Así, el ejercicio de ciertos derechos dejaría de conculcarse, pues son desincentivados por la obligación impuesta a la autoridad o a particulares de verificar el estado de la situación migratoria. Por ejemplo, la obligación de avisar el término de un contrato de 
trabajo o condicionar ciertos derechos sociales a la verificación de la situación migratoria. Reiteramos que los derechos contenidos en la Constitución o en otros pactos de derechos humanos son exigibles por el migrante en su condición de persona y no están condicionados por su situación legal.

Finalmente, el derecho a retornar al país de origen ya ha sido desarrollado por los instrumentos internacionales (Chueca y Aguelo, 2013, p. 10).

Ahora bien, los derechos fundamentales no son absolutos y pueden ser limitados:

La concepción absoluta del contenido esencial de un derecho fundamental es precisamente la que establece una conexión con el concepto de garantías institucionales y de instituto, y sostiene la posibilidad de distinguir un núcleo básico que hace identificable a un derecho fundamental como tal. El objeto protegido, desde esta concepción, no es el derecho subjetivo de cada individuo, sino la configuración jurídica del respectivo derecho. (Aldunate, 2008, p. 262).

De acuerdo con Tórtora (2010), las limitaciones a los derechos fundamentales son

aquellas restricciones al ejercicio de un determinado derecho básico, de manera tal que toda pretensión de ejercicio del atributo respectivo que vulnere los límites impuestos por las mismas, es por esencia antijurídica y puede derivar para el titular infractor, en las responsabilidades que para tal efecto, prevea el ordenamiento jurídico positivo. (p. 169).

Por su parte, para Aguelo y Granero (2017)

no es fácil definir todos y cada uno de los posible límites que puede sufrir la persona que intente ejercer su "ius migrandi”. Ya desde Vitoria se afirma de modo inequívoco que el establecimiento deberá ser pacífico, amistoso y mutuamente respetuoso: hoy debemos observar que tal establecimiento debe realizarse sin más barrera que los propios Derechos Humanos. Y esta barrera no podrá ser superada ni siquiera por presuntas razones de lucha contra el terrorismo. (p. 86).

Desarrollando dicha idea, señalan que esos límites son los deberes impuestos en la CTM a los trabajadores migrantes (p. 87). Chueca y Aguelo, a nuestro juicio, abordan adecuadamente el tema. A partir de los artículos 12 y 13 de la CTM se pueden establecer: límites en concreto:

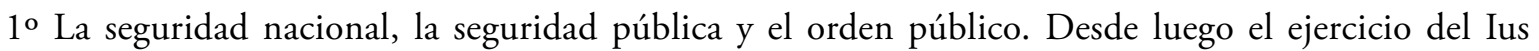
Migrandi puede limitarse si pone en peligro la seguridad nacional, la seguridad pública o el orden público. Así sucede en los casos en los que se prueben actividades terroristas o delincuencia común (individual o en grupo).

$2^{\circ}$ La salud pública y la moral pública. Las epidemias o las enfermedades infectocontagiosas suelen limitar en un momento dado el ejercicio de este Derecho.

$3^{\circ}$ La prohibición de toda propaganda a favor de la guerra y de la apología del odio nacional, racial o religioso, que (aun cuando el texto convencional no resulte tan explícito) siempre incita a la discriminación, la hostilidad y la violencia.

\subsubsection{Efectos del ius migrandi como derecho fundamental}

Concebir el derecho a migrar en los términos en que ha sido expuesto generará consecuencias jurídicas evidentes. Se incorporará al plexo de derechos fundamentales y, en consecuencia, compartirá sus 
características. Constituirá por tanto un mandato de optimización, con todo lo que implica, y deberá procederse a su máxima realización posible. Servirá de principio en la interpretación de la legislación de extranjería, debiendo utilizar el principio propersona y el principio de interpretación conforme a los derechos humanos, tanto en sede administrativa como jurisdiccional. Así también gozarán de la protección que se otorga a los derechos fundamentales.

La actual Ley de Extranjería resultará en la práctica inaplicable, por cuanto sus preceptos escasamente satisfacen los requerimientos de una normativa acorde a un enfoque de derechos humanos. Gran parte de las regulaciones infralegales dejarán de tener efecto acorde al principio de reserva legal, respecto de derechos fundamentales: "toda ley que constituya una limitación a los derechos fundamentales debe cumplir con los requisitos fijados por el artículo $19 \mathrm{n}^{\circ} 26$ del texto constitucional: reserva legal, no afectación al contenido esencial del derecho limitado y proporcionalidad” (Molina, 2020, p. 304).

En síntesis, el Estado se verá forzado a modificar la normativa que regula la materia, reconociendo el derecho fundamental a migrar y adecuando los preceptos con esta nueva realidad, tal como ya han efectuado países como Argentina, Bolivia, Ecuador, México y Uruguay.

\section{Conclusiones}

Como se ha expuesto, la movilidad humana es un proceso que ha acompañado el desarrollo de la humanidad desde antiguo y que con toda seguridad seguirá existiendo. Responderá a sus propias motivaciones, más allá de las teorizaciones que efectúan las ciencias sociales y mucho más allá de las limitaciones y regulaciones que propongan los Estados. En las últimas décadas, estos —a través de sus ordenamientos jurídicos- y los órganos internacionales — por medio de los instrumentos de derechos humanos desarrollados- han contribuido a consolidar el derecho de los migrantes al restringir la entrada a su territorio, en base al concepto de soberanía. Así, las categorizaciones creadas por el derecho respecto de las personas (nacional, extranjero, migrante en situación regular o irregular) están fuertemente arraigadas.

Un examen del derecho a migrar, a partir de algunas fuentes y reflexiones, permite inferir que la mayor parte del tiempo ha sido entendido como inherente al ser humano, no requiriendo mayores esfuerzos por argumentar o dejarlo explícito en las normas. A partir de la configuración del Estado nación y principalmente desde la segunda postguerra, el derecho a migrar ha sido relegado a un segundo o tercer plano, dando preeminencia a las facultades estatales. El reconocimiento de la dignidad humana como fuente de los derechos humanos, a nuestro juicio, debiese oponerse a esta facultad estatal. Sin embargo, se ha complementado con ella, reconociéndola y consolidándola. No deja de ser un fenómeno llamativo que la dignidad humana sea límite de la soberanía, pero que en materia migratoria ceda abiertamente frente a ella.

Un estudio de la concepción de la dignidad humana, unida a la libertad de circulación —ambos principios ampliamente aceptados - permite deducir que el derecho a migrar es inherente a la naturaleza humana y en el contexto actual del ordenamiento jurídico corresponde a un derecho implícito. Si bien la concepción de derechos implícitos no goza de una recepción dominante en la doctrina, creemos que una interpretación finalista de los derechos del ser humano como centro del derecho debe reconocer la existencia de tales derechos.

Consecuencia del derecho a migrar como derecho fundamental es su exigibilidad erga omnes. Así, el Estado debe adecuar sus normas a esta concepción. Los órganos administrativos y los jurisdiccionales deben interpretar los preceptos desde un enfoque de derechos humanos, reconociendo así algo que en 
apariencia es evidente, pero en la práctica es negado: las personas son iguales en dignidad y derechos, independiente de su lugar de origen.

\section{Bibliografía}

Aguelo Navarro, Pascual y Granero Sánchez, Hipólito (2017): "Los muros fronterizos desde la perspectiva jurídica del ius migrandi”, MODULEMA Revista Cientifica sobre Diversidad Cultural, Vol. 1: pp. 61-94.

Aguerre, Lucía (2018): El fenómeno migratorio y su relación con la crisis de la noción moderna de ciudadania: análisis de tres propuestas (Buenos Aires, TeseoPress).

Aguilar Cavallo, Gonzalo (2010): "Derechos fundamentales-derechos humanos ¿Una distinción válida en el siglo XXI?”, Boletín Mexicano de Derecho Comparado, Vol. 43, No 127: pp. 15-71.

Aldunate Lizana, Eduardo (2008): Derechos fundamentales (Santiago, Legal Publishing).

Aninat, Isabel y Sierra, Lucas (2019): "Regulación inmigratoria: propuestas para una mejor reforma", en Aninat, Isabel y Vergara, Rodrigo (eds.), Inmigración en Chile: una mirada multidimensional (Santiago, Fondo de Cultura Económica Chile), pp. 31-64.

Arce Jiménez, Carlos (2018): "Migraciones, derechos humanos y vulnerabilidad", Revista de Fomento Social, No 289: pp. 115-140.

Arcos Ramírez, Federico (2020): “¿Existe un derecho humano a inmigrar? Una crítica del argumento de la continuidad lógica”, Doxa - Cuadernos de Filosofía del Derecho, No 43: pp. 285-312.

Bellolio Avaría, Álvaro y Valdés Edwards, Gonzalo (2020): Gestión de la migración en el s. XXI. El caso de Chile (Chile, Subsecretaría del Interior Gobierno de Chile).

Bidart Campos, Germán (2002): "Los derechos 'no enumerados' en su relación con el Derecho Constitucional y el Derecho Internacional”, Derecho \& Sociedad, No 18: pp. 256-261.

Candia Falcón, Gonzalo (2015a): “Analizando la tesis de los derechos implícitos: comentario a la sentencia del Tribunal Constitucional recaída sobre el requerimiento de inaplicabilidad rol $\mathrm{N}^{\circ} 2.408-2013 \mathrm{de}$ 6 de marzo de 2014", Revista de Derecho (Coquimbo), Vol. 21, No 1: pp. 497-521.

Candia Falcón, Gonzalo (2015b): "Derechos Implícitos y Corte Interamericana de Derechos Humanos: una reflexión a la luz del concepto de estado de derecho", Revista Chilena de Derecho, Vol. 42, No 3: pp. 873-902.

Castillo Córdova, Luis (2008): "Justificación y significación de los derechos constitucionales implícitos", Gaceta constitucional: jurisprudencia de observancia obligatoria para abogados y jueces, 5: pp. 31-48.

CEPAL (2008): América Latina y el Caribe: migración internacional, derechos humanos y desarrollo (Santiago, Naciones Unidas).

Chávez-Fernández Postigo, José y Ríos Carrillo, Piero (2019): "De la tesis de la doble naturaleza de Alexy a un Iusnaturalismo moderado: una propuesta de comprensión de los derechos fundamentales implícitos a partir de la jurisprudencia de constitucional de Perú y Chile", Revista Chilena de Derecho, Vol. 46, No 1: pp. 177-201.

Chueca Sancho, Ángel y Aguelo Navarro, Pascual (2013): “Contenido y límites del Ius Migrandi”, Revista Electrónica Iberoamericana, Vol. 7, № 2: pp. 6-15.

Contreras Vásquez, Pablo (2011): “¿Derechos implícitos? Notas sobre la identificación de normas de Derecho Fundamental”, en Núnez Leiva, José Ignacio (ed.), Nuevas Perspectivas en Derecho Público (Santiago, Editorial Librotecnia), pp. 149-185. 
Corchete Martín, María José (2007): “Los nuevos derechos”, Teoría y Realidad Constitucional, No 20: pp. 535-556.

Díaz Tolosa, Regina (2020): "Una nueva institucionalidad para la protección de los derechos de las personas migrantes en Chile", Revista Justicia y Derecho, Vol. 3, No 1: pp. 67-97.

Díaz Tolosa, Regina (2016): "Ingreso y permanencia de las personas migrantes en Chile: compatibilidad de la normativa chilena con los estándares internacionales", Estudios constitucionales, Vol. 14, No 1: pp. 179-220.

Díez-Picazo, Luis (2008) Sistema de derechos fundamentales (Madrid, Thomson Civitas).

Domínguez Valverde, Cecilia (2016): "Derecho chileno migratorio a la luz del derecho migratorio internacional: ¡ceden los derechos humanos mínimos de los extranjeros antes las prerrogatvas soberanas de control migratorio?”, Revista Chilena de Derecho, Vol. 43, No 1: pp. 189-217.

Ferrajoli, Luigi (2019): "Políticas contra los migrantes y crisis de la civilización jurídica", Revista peruana de derecho constitucional - Migración y derechos fundamentales, pp. 29-52.

García, Lila (2020): "Estándares del Sistema Interamericano de Derechos Humanos sobre garantías del debido proceso en el control migratorio", Estudios de Derecho, Vol. 77, No 169: pp. 119-144.

García, Lila (2016): "Migraciones, Estado y una política del derecho humano a migrar. ¿Hacia una nueva era en América Latina?”, Colombia Internacional, No 88: pp. 107-133.

Gros Espiell, Héctor (2000): "Los derechos humanos no enunciados o no enumerados en el constitucionalismo americano y en el artículo 29.c) de la Convención Americana sobre Derechos Humanos", Anuario Iberoamericano de Justicia Constitucional, No 4: pp. 145-172.

Guastini, Riccardo (2011): “Derechos implícitos”. Disponible en: https://web.ua.es/es/observatoriodoxa/ documentos/comentario-riccardo-guastini.pdf. [Fecha de consulta: 26/01/2021].

Gutiérrez Moya, Carlos (2017): "La expulsión como pena contra un inmigrante: ¿es un castigo o un premio para el condenado extranjero sin residencia legal?”, Ars Boni et Aequi, Vol. 13, No 1: pp. 95-130.

Juste Ruiz, José (2019): "El Derecho internacional de las migraciones: entre la crisis y la renovación", Anuario Español de Derecho Internacional, Vol. 35: pp. 535-551.

Magallanes Martínez, Víctor (2016): "Contenido esencial de los derechos fundamentales y juez constitucional”, Revista del Instituto de la Judicatura Federal, No 41: pp. 235-270.

Minay, Sebastián y Muñoz, Andrés (2018): ¿Es la migración un derecho humano? Qué dicen los especialistas. La Tercera, 10 diciembre 2018. Disponible en: https://www.latercera.com/la-tercera$\mathrm{pm} /$ noticia/es-la-migracion-un-derecho-humano-que-dicen-los-especialistas/438384/. [Fecha de consulta: 25/01/2021].

Molina Conzué, Diego (2020): "La medida de expulsión administrativa de extranjeros en el derecho chileno: límites materiales y formales”, Estudios de Derecho, Vol. 77, No 169: pp. 293-321.

Morales Vega, Luisa (2016): "Las migraciones, al amparo del régimen internacional de los Derechos Humanos. Utopías concurrentes”, Colombia Internacional, No 88: pp. 213-229.

Morales Vega, Luisa y Sanromán Aranda, Roberto (2016): "Derechos humanos y seguridad nacional en México. Programa Frontera Sur a cuatro años de la Ley de Migración”, Anuario Mexicano de Derecho Internacional, Vol. 16: pp. 345-372.

Nieves Hernández, Efraín (2014): ¿Derecho internacional a migrar? Entre el derecho natural y el derecho positivo: el dilema de los derechos humanos de los migrantes", Revista de Relaciones Internacionales de la UNAM, No 120/121: pp. 49-76. 
Nogueira Alcalá, Humberto (2015): "El bloque constitucional de derechos en Chile, el parámetro de control y consideraciones comparativas con Colombia y México: doctrina y jurisprudencia”, Estudios constitucionales, Vol. 13, No 2: pp. 301-350.

Nogueira Alcalá, Humberto (2007): "El derecho a la propia imagen como derecho fundamental implícito", Ius et Praxis, Vol. 13, No 2: pp. 245-285.

Nogueira Alcalá, Humberto (2002): "La libertad personal y las dos caras de Jano en el ordenamiento jurídico chileno", Revista de Derecho, Vol. 13: pp. 161-186.

OIM y IPPDH (2017): Derechos humanos de personas migrantes. Manual Regional. Disponible en: https:// publications.iom.int/es/system/files/pdf/derechos_humanos_de_personas_migrantes-manual_ regional.pdf [Fecha de consulta: 26/01/2021].

OIM y IPPDH (2016): Migración, derechos humanos y politica migratoria, cuadernillo 1. Disponible en: https:/www.ippdh.mercosur.int/wp-content/uploads/2017/02/Migraci\%C3\%B3n-derechoshumanos-y-pol\%C3\%ADtica-migratoria.pdf [Fecha de consulta: 26/01/2021].

Penchaszadeh, Ana (2016): "Excepcionalidad y migraciones. Reflexiones en torno de los procesos de desnacionalización masiva de personas de ascendencia haitiana en República Dominicana”, Migraciones Internacionales, Vol. 8, No 31: pp. 269-278.

Straehle Porras, Edgar (2018): "Europa frente a los refugiados: releer los derechos humanos desde Hannah Arendt", Lectora: Revista de Dones i Textualitat, No 24: pp. 61-81.

Tórtora Aravena, Hugo (2010): "Las limitaciones a los derechos fundamentales", Estudios constitucionales, Vol. 8, No 2: pp. 167-200.

Varas Alfonso, Paulino (1993): "Respeto a todo derecho inherente a la persona, aunque no está reconocido en el texto de la Constitución”, Revista Chilena de Derecho, Vol. 20, No 2-3: pp. 723-729.

Velasco, Juan (2016): “Open-Border Immigration Policy: A Step towards Global Justice”, Migraciones Internacionales, Vol. 8, No 4: pp. 41-72.

Vitoria, Francisco de (1975): Relecciones sobre los indios y el derecho de guerra (Madrid, Espasa-Calpe, 3a ed.).

World Bank Data Team (2019): "Nueva clasificación de los países según el nivel de ingresos para 2019 y 2020". Disponible en: https://blogs.worldbank.org/es/opendata/nueva-clasificacion-de-los-paisessegun-el-nivel-de-ingresos-para-2019-y-2020 [Fecha de consulta: 25/01/2021]. 